\title{
Identifying gaps in existing Early Warning Mechanisms and Evacuation Procedures for Tsunamis in Sri Lanka with a special focus on the use of Social Media
}

Ravindu Udayantha Jayasekara, Department of Civil Engineering, University of Moratuwa, Sri Lanka

Gaindu Saranga Jayathilaka, Department of Civil Engineering, University of Moratuwa, Sri Lanka

Chandana Siriwardana, Department of Civil Engineering, University of Moratuwa, Sri Lanka

Dilanthi Amaratunga, University of Huddersfield, United Kingdom

Richard Haigh, University of Huddersfield, United Kingdom

Chaminda Bandara, Department of Civil Engineering, University of Peradeniya, Sri Lanka

Ranjith Dissanayake, Department of Civil Engineering, University of Peradeniya, Sri Lanka

\section{Citation}

Jayasekara, R.U., Jayathilaka, G.S., Siriwardana, C., Amaratunga, D., Haigh, R., Bandara, C. and Dissanayake, R. (2021), "Identifying gaps in early warning mechanisms and evacuation procedures for tsunamis in Sri Lanka, with a special focus on the use of social media", International Journal of Disaster Resilience in the Built Environment, Vol. ahead-of-print No. ahead-of-print. https://doi.org/10.1108/IJDRBE-02-2021-0012

\begin{abstract}
Purpose

National Early Warning (EW) System in Sri Lanka was established after the devastations of the Indian Ocean Tsunami in 2004. Although EW and evacuation procedures are in place, several areas which need improvements have been emphasized in recent studies carried out in the country. Therefore, this paper attempts to outline gaps in existing EW and EP related to tsunami and other coastal hazards with a special focus on the use of social media for disaster communication based on age groups.
\end{abstract}

\section{Design}


The study has drawn on a review of past studies carried out by the same research team to identify the scope of the study. In addition to that, a conceptual framework was developed for the use of social media in the event of a disaster. Based on this conceptual framework, an online questionnaire was administered to identify the current status of the use of social media in Sri Lanka during a disaster situation. In total, 408 responses were collected and analysed using the Binary logistic regression method to evaluate the variation of different predictors associated with the use of social media for disaster communication.

\section{Findings}

Findings of the study revealed that the use of social media for disaster communication depends on the previous experience of users and their age. The gender of users does not affect the use of social media for disaster communication. Therefore, accuracy, and timeliness of disaster information distributed via social media should be improved further to enhance the use of social media for disaster communication. Moreover, the findings have highlighted unaddressed issues in areas such as governance; communication of technical agencies; evacuation and shelters; and response of the community.

\section{Originality/Value}

This paper has identified key areas that need attention in the process of enhancing the use of social media for disaster communication. More use of technological platforms such as social media for receiving disaster-related information can address issues such as bottlenecks in communication, poor awareness, and lack of last-mile dissemination. Furthermore, this paper has proposed recommendations for addressing the identified gaps in the overall EW mechanisms and EP pertaining to tsunamis and other coastal hazards to enhance the coastal disaster resilience in Sri Lanka.

\section{Introduction}

Recently, the frequency of occurrence of hazards such as floods, landslides, high winds fires, etc. in Sri Lanka and their extremity has increased rapidly. Climate change, growing population, rapid 
urbanization, and many other natural and man-made activities are the main causes of this increase (JICA, 2017; Shehara et al., 2019a). According to the Global Climate Risk Index 2019, Sri Lanka was ranked as the second most affected country by climate change in the year 2017 (Eckstein et al., 2019). Coastal areas of Sri Lanka have been affected severely by various types of hazards and their subsequent disasters. Although tsunami has been categorized as an infrequent hazard in Sri Lanka it has the most crucial impact on the country which can be caused by a disaster. The Indian Ocean Tsunami (IOT 2004), left Sri Lanka with over 30,000 people dead in coastal areas, almost a million displaced and an estimated 150,000 people lost their primary source of livelihood. There was massive damage to infrastructure and capital assets; estimated at around US\$1 billion (4.5\% of GDP), particularly in tourism and fisheries which are the major income sectors in the coastal areas (Jayasuriya et al., 2006).

With the colossal impacts of the IOT (2004), several strategies have been taken by the Sri Lankan government and other relevant stakeholders to minimize damages and losses from future tsunamis and other possible hazards. Being a part of the Indian Ocean Tsunami Early Warning and Mitigation System (IOTEWMS) is one of the major steps among them (Jayasiri et al., 2018a). Sri Lanka established the National Early Warning System (NEWS: SL) under the legal provisions made by Act No.13 of 2005 (Jayasiri et al., 2018b). Through this existing mechanism, Disaster Management Centre; which was established under the said Act, is informed regarding an impending disaster and initiates the process of warning dissemination while communicating with the Emergency Operations Centre [EOC]. EOC is responsible to disseminate warnings to administrative divisions such as provincial councils, district secretariats, and divisional secretariats via different modes of channels (JICA, 2017). With the warning issued via this process, relevant other government and non-government authorities take actions related to the evacuation and other rehabilitation procedures.

However, the effectiveness of the existing Early Warning System for Tsunami and other coastal hazards was questioned several times. Several studies that were conducted to identify barriers and enablers in coastal disaster resilience have highlighted existing gaps in the Early Warning (EW) and Evacuation Procedures (EP) pertaining to coastal hazards (Perera et al., 2020; Rathnayake et al., 2020). These gaps and provided recommendations are identified mainly under key themes such as governance, modes of EW and EP dissemination, and the response of authorities and 
community. However, a limited number of attempts are taken to investigate gaps related to the use of social media in the EW and EP dissemination and impacts of pandemics on response mechanisms for tsunami and other hazards. Therefore, this paper has aimed to outline a holistic view of gaps and barriers in EW and EP in Sri Lanka related to tsunami and other coastal hazards with recommendations while having a special focus on addressing issues related to the use of social media and impacts of the COVID-19 and other pandemics.

\section{Tsunami Early Warning Systems (TEWS) and their elements}

The bleak effects of tsunamis can be mitigated through community resilience, efficient early warnings, and effective response although their occurrence cannot be prevented (Cecioni et al., 2014). Tsunamis rapidly propagate after their occurrence and reach coastal lands within a shorter period of time. For instance, the tsunami arrival time in Indonesia is 10-60 minutes in general (Yunarto and Sari, 2018). Therefore, Tsunami Early Warning Systems (TEWS) play a key role related to rapid warning dissemination and execution of EP. An end-to-end TEWS starts with detecting a possible tsunami and ends with the safe return of evacuated people to their original residents (Leon et al., 2006). There are two phases named, upstream and downstream in a TEWS. Detection of the earthquake, prediction of tsunamis, and delivering the warning to national warning centres of member countries are completed at the upstream phase (IOC/UNESCO, 2015). The downstream phase involves the dissemination of EW and EP to the public after evaluating the relevant impact of the tsunami (Bernard and Titov, 2015). However, the decisions to issue warnings and orders for evacuation take place in a different phase in between upstream and downstream phases; called the interface (Haigh et al., 2020). An effective TEWS shows key characteristics such as fast and accurate prediction and forecasting, efficient alarming, and effective response (Cecioni et al., 2014).

Individual countries have the responsibility to manage challenges related to disseminating EW and EP (International Tsunami Information Center, 2021). Currently, countries such as the United States of America, India, and Japan have implemented advanced TEWS to disseminate timely warnings to their citizens. For an instance, the USA continues monitoring its coasts, and British Columbia, Puerto Rico, and the Virgin Islands employ a sophisticated multi-channel communication system (Lancaster, 2020). Japan has a nationwide combined alert system for tsunami and earthquakes which employs advanced mobile applications (Komoriya, 2018). Since, 
a nationwide TEWS engages a large variety of stakeholders and different supporting agencies and experts, coordination between responsible stakeholders is paramount (Haigh et al., 2020). In the absence of inadequate human assets and effective technological applications, this coordination can fail, rendering the failure of the whole early warning system (Leon et al., 2006). Taking fast and accurate decisions is a must within a TEWS to warn and evacuate vulnerable communities in a timely manner (Rasquinho et al., 2012). Hence, it is evident that governing administrative structures and policy and legal frameworks have been vested with key responsibilities in TEWS.

Currently, most of the countries have directed their focus on advancing their modes of communication used for EW dissemination. This is a result of identifying the benefits of the use of new technology to enhance the efficiency of delivering modes of EWs (Shehara et al., 2019a). In the process of evacuation and sheltering, issues related to areas such as public awareness, people with special needs, relief services, etc. have emerged (Rathnayake et al., 2020). Furthermore, the human factor [i.e.; capacity to respond] also has a considerable impact on a people-centric approach to disaster resilience (Leon et al., 2006). Last but not least the impacts of health emergencies such as COVID-19 on response capacities to tsunamis should be taken into consideration within TEWS (Amaratunga et al., 2020b). Hence, an effective TEWS must consider key themes such as the efficiency of governance, communication between technical agencies, use of technological platforms for EW dissemination, government response for EW, and community response for EW and EP [i.e., reluctance, people with special needs].

\section{Sri Lankan Tsunami Early Warning System}

The Indian Ocean Tsunami (IOT) 2004 had its bleak effects on coastal areas of Sri Lanka causing over 35,000 deaths and rendering more than 500,000 people homeless (Pattiaratchi, 2005). Coastal inundation resulted in severe damages to properties including buildings, roads, bridges, railways, ports, etc. (Tomita et al., 2006). Before the IOT (2004) risk of tsunamis as a coastal hazard was not taken into consideration satisfactorily. Its devastating impacts called for the need for a TEWS in the Indian Ocean. Therefore, the Indian Ocean Tsunami Early Warning and Mitigation System (IOTWMS) was established in 2008 and operationalized fully in 2013. All the member states of this system, including Sri Lanka, are vested with the responsibility of identifying tsunami hazards, assessing the risk, and issuing early warnings to their communities with the assistance of three Tsunami Service Providers (TSPs) [India, Indonesia, and Australia] (UNESCO, 2019). The 
Intergovernmental Oceanographic Group/ Indian Ocean Tsunami Warning and Mitigation System (ICG/IOTWMS) has been subsequently testing its end-to-end TEWS in the Indian Ocean-wide tsunami warning and response exercise (IOWave09) since 2009.

The plate boundary which is located near Indonesia, Sumatra, Nicobar, and Andamans, is the most active plate boundary in the world currently and it is $1000 \mathrm{~km}$ away from Sri Lanka. Furthermore, Sri Lanka has its highest risk index for tsunamis among all types of disasters (8.9 out of 10) (Amaratunga et al., 2020b). Wijetunge, (2012) has revealed that an event similar to the IOT 2004 in Sumatra- Andaman area can be recognized as the worst tsunami scenario for Sri Lanka. Though the return period of tsunamis may be many years if an earthquake occurs at any time a tsunami can generate. Therefore, Sri Lanka has the responsibility to continuously practise and update its TEW and Evacuation procedures. Because of the dire need for enhancing the resilience of coastal areas in Sri Lanka for tsunamis and other coastal hazards, several studies have been conducted on gaps that hinder effective preparedness and response mechanisms. Furthermore, observations of the Indian Ocean-wide tsunami warning and response exercise 2020 have also highlighted several areas of the National Tsunami Early Warning System that need improvements. Identified gaps of past studies can be presented under five themes as described in Table 1.

Table 1: Selected themes for identifying gaps and their justifications

\begin{tabular}{|c|c|c|}
\hline \multicolumn{2}{|c|}{ Theme } & Justification \\
\hline \multirow[t]{2}{*}{ 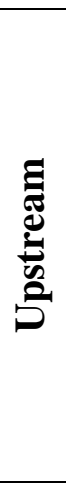 } & Governance & $\begin{array}{l}\text { Governance can be identified as a key aspect of Disaster Risk } \\
\text { Reduction (DRR) at both policy level and individual warning } \\
\text { systems. Therefore, gaps and strengths in legal frameworks, } \\
\text { institutional hierarchy, and main actors should be identified } \\
\text { under this theme. }\end{array}$ \\
\hline & \multirow{2}{*}{$\begin{array}{l}\text { Communication } \\
\text { between technical } \\
\text { agencies }\end{array}$} & \multirow{2}{*}{$\begin{array}{l}\text { Multi-Hazard Early Warnings clearly defines communication } \\
\text { networks and enhances the effectiveness of communication } \\
\text { mechanisms. In this regard, it is essential to identify the behavior } \\
\text { of the network of stakeholders and their influence related to } \\
\text { communication. }\end{array}$} \\
\hline 递 & & \\
\hline
\end{tabular}




\begin{tabular}{|l|l|l|}
\hline \multirow{2}{*}{$\begin{array}{l}\text { Modes of EW } \\
\text { dissemination }\end{array}$} & $\begin{array}{l}\text { Early warnings and evacuation orders should be disseminated to } \\
\text { the public timely and accurately. In this regard, modes of EW } \\
\text { dissemination have to play a major role. Therefore, gaps in } \\
\text { dissemination modes should be identified to enhance the } \\
\text { efficiency of EW dissemination, }\end{array}$ \\
\cline { 1 - 3 } & $\begin{array}{l}\text { Response of } \\
\text { authorities }\end{array}$ & $\begin{array}{l}\text { In the process of evacuation and sheltering, issues related to } \\
\text { areas such as public awareness, people with special needs, relief } \\
\text { services, etc. can emerge. Therefore, this scenario calls for the } \\
\text { need for identifying the gaps and strengths related to evacuation } \\
\text { plans, routes, shelters, and drills. }\end{array}$ \\
\cline { 2 - 5 } & $\begin{array}{l}\text { Response of } \\
\text { community }\end{array}$ & $\begin{array}{l}\text { The effectiveness of community response is a key factor in EW } \\
\text { public awareness, knowledge, and willingness regarding EW and } \\
\text { EP positively affect the effectiveness of the process. }\end{array}$ \\
\hline
\end{tabular}

\subsection{Governance}

Currently, Sri Lanka has a comprehensive Early Warning System (EWS) that operates from the national level to sub-national levels. In this National Early Warning System (NEWS), the Emergency Operation Centre (EOC) which is under the purview of the Disaster Management Centre acts as the focal point for coordinating EW messages at the national level and ensures the last-mile dissemination of EWs (Disaster Management Centre, 2020a, 2015). DMC functions as the executing agency of DM mechanism in Sri Lanka. As stipulated in the National Disaster Management Plan, the Department of Meteorology (DoM) as the National Tsunami Warning Centre (NTWC) for Sri Lanka, has been vested with the responsibility of forecasting and issuing EW messages on tsunamis (Disaster Management Centre, 2014). It receives the warning message from TSPs and after verifying passes it to the DMC to disseminate through the NEWS. DMC has 
recently developed Standard Operation Procedures (SOPs) and Emergency Operation Procedures (EOPs) to be followed for the TEW process (Disaster Management Centre, 2020b, 2015).

However, past studies have highlighted that power struggles between government authorities engaged in the EW process of the country have caused a significant decrease in the effectiveness of governance (Haigh et al., 2018). Since the enactment of the Disaster Management Act No. 13 of 2005, practitioners have been more focused on developing technical aspects than administrative aspects (Birkmann et al., 2010). Furthermore, the observer report of the Indian Ocean Wide Tsunami exercise 2020 [IOWave20] which was conducted in Sri Lanka recently, emphasizes the absence of a Technical Advisory Committee to make decisions and lack of training of officials at DoM. The need for testing SOPs to reflect current roles and responsibilities and lack of technological methods for data monitoring and information feeding have also been highlighted during the IOWave20 exercise (Amaratunga et al., 2020b).

Moreover, the occurrence of multiple hazards concurrently and cascading impacts of the COVID19 pandemic have highlighted the need for reconfiguring risk governance to address systemic risks (Quigley et al., 2020). Several countries such as India and Vanuatu were benefited from their strengthened legal and policy provisions of disaster management during multiple disasters that have occurred amidst the COVID-19 pandemic (UNDRR, 2020a; UNDRR and OCHA, 2020). Furthermore, the need for following Bangkok Principles for the implementation of health aspects of the Sendai Framework for Disaster Risk Reduction 2015-2030 was significantly highlighted during the pandemic (UNDRR, 2020b). These principles emphasize the necessity of integrating health into disaster management policies and plans at national and local levels for emulating multisectoral approaches (UNISDR, 2016). In Sri Lanka, preparedness activities targeting biological hazards are predominantly carried out by public health authorities. The need for taking actions to develop and implement a multi-sectoral mechanism has been extremely emphasized recently (Amaratunga et al., 2020a). Furthermore, observations of IOWave20 also call attention to addressing gaps in the communication chain with the health sector amidst a health crisis such as COVID-19 as impacts of a health emergency can limit the use of resources of health authorities (Amaratunga et al., 2020b).

\subsection{Communication network between stakeholders}


Barriers in communication networks between stakeholders might be bottlenecks and reduce the efficiency of the entire EW dissemination process (Sakamoto et al., 2016). In the Sri Lankan context, Shehara et al., (2019b) have modelled the communication network of stakeholders for five frequent hazards in Sri Lanka including Tsunami using Social Network Analysis (SNA) [see Figures 1 and 2]. Results of the study have revealed that DMC functions as the key centralized stakeholder with the responsibility of receiving TEWs from DOM and dissemination of these warnings to respected units (Shehara et al., 2019b). Furthermore, the analysis shows the higher complexity in following Emergency Operation Procedures than Standard Operation Procedures.

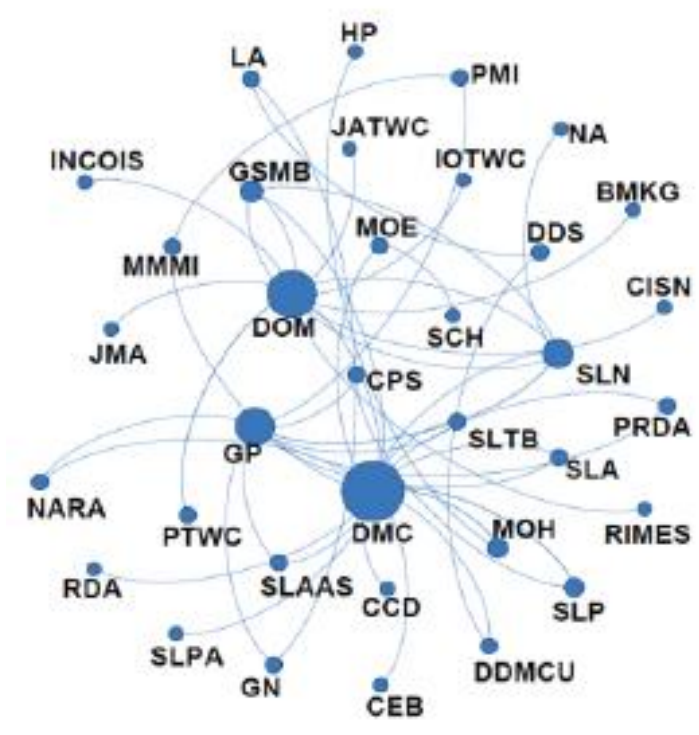

Figure 1: Communication Network Developed for Tsunami Based on EOPs (Shehara et al., 2019b)

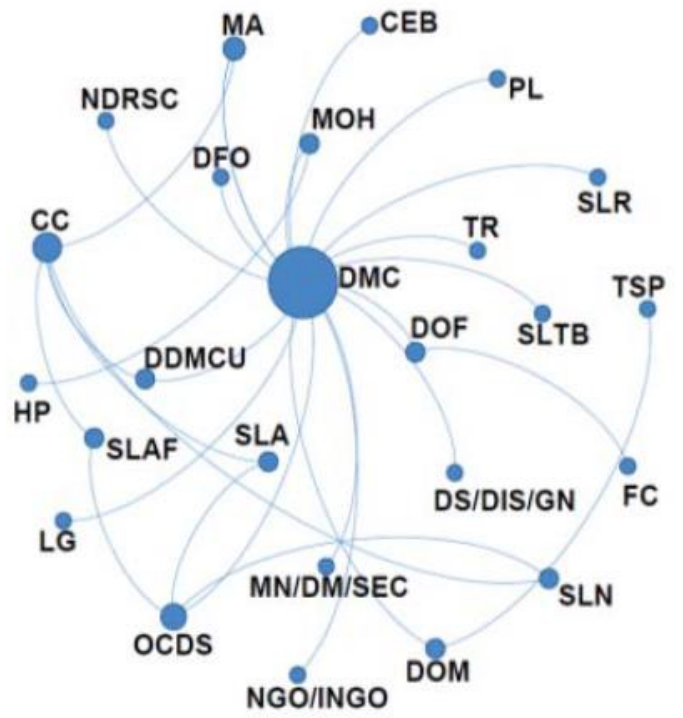

Figure 2: Communication Network Developed for Tsunami Based on SOPs (Shehara et al., 2019b)

Since the COVID-19 outbreak has affected the response mechanisms for concurrent hazards, it is better to direct the focus towards the impacts of pandemics on the communication network of stakeholders (Okura et al., 2020). The effective involvement of key stakeholders is paramount in enhancing the resilience against possible concurrent hazards such as Tsunamis amidst the pandemic (UNDRR, 2020a). In such a multiple disaster situation, strong coordination between line ministries, and partners at regional levels is significant. Especially, collaboration between health officials and disaster management authorities stands pivotal in this regard (UNDRR and OCHA, 2020). Recent studies conducted in Sri Lanka highlight that public health authorities have the highest control over the flow of information in the communication network during an epidemic. However, the link between health officials and other stakeholders in a multi-hazard context should be further strengthened (Jayasekara et al., 2021). 


\subsection{Modes of EW dissemination and use of new technologies for disaster communication}

'Warning, dissemination, and communication' is one of the key elements in an MHEW system (WMO, 2018). Existing communication channels that are used for disaster communication can be divided into two as traditional media (old media) and modern media (new media) (Feldman et al., 2016). Traditional media can be considered as any form of mass communication that was available before the advent of digital media. It has been widely used to distribute disaster information before the $21^{\text {st }}$ century (Johnson, 2015). Currently, dedicated mobile applications and social media have become the most efficient and popular in terms of emergency response and disaster informationsharing platforms globally (Shehara et al., 2019a). However, a recent study carried out in the coastal areas of Sri Lanka has concluded that the use of modern communication channels for disaster communication is low at the village level for disaster communication (Perera et al., 2020). Though the use of modern media is lacking at the village level Shehara et al., (2021) reveal that the community has been favourable towards adapting to the new approaches in the dissemination of EW alerts such as mobile applications.

Recently, social media has been widely used in disasters for communication purposes over traditional media worldwide (Peary et al., 2012). Compared to traditional media, social media has shown a vast range of benefits in terms of adaptability, relevance for residents, empowerment, information control, dependency on the power grid, cost, accessibility, and timeliness (Keim and Noji, 2011). Some incidents have shown that social media is the only way to communicate although traditional media exists (Acar and Muraki, 2011). As a multi-directional communication mechanism, it has an advanced capacity to interact with a massive community which is productive in information dissemination (Shneiderman and Preece, 2007). Finau et al., (2018) reveal that social media has contributed to information-sharing before, during, and after Tropical Cyclone Winston innovatively and efficiently. Furthermore, Hazarika et al., (2020) illustrate that social media has influenced the effective engagement of disaster relief services during Hurricane Harvey.

Recently, there has been a high usage of social media during disaster and post-disaster phases in Sri Lanka. During the 2016 floods in Sri Lanka, social media become the main form of communication (Jayasekara, 2019). However, the use of social media for EW dissemination is considerably low. Recent studies conducted in Sri Lanka highlight that a considerably low percentage of the public uses social media for disaster communication (Shehara et al., 2021, 2020). 
In addition to that, lack of reliability in EW messages and risk information, and monetary issues affect the use of social media for risk communication in Sri Lanka. The tendency for spreading false information via social media is considerably high in the Sri Lankan context. Therefore, the commitment of authorities towards social media for EW dissemination has also gone down (Fernando, 2020). Implementing a proper regulating mechanism to avoid spreading misinformation and conducting awareness programs to the general public about the use of social media during disasters are some of the key suggestions proposed to address these existing issues.

\subsection{Response of authorities}

Although Sri Lanka has showcased the efficiency of its existing EW mechanisms several times, recent studies have stressed on several gaps in the existing process of evacuation planning in the country (Hettiarachchi and Weerasinghe, 2014). In general, properly planned evacuation shelters pave way for well-structured rehabilitation and reconstruction activities (Mulligan and Nadarajah, 2012). However, according to the general public in coastal areas of Sri Lanka, most of the shelters lack facilities and utilities. Lack of space, drinking water, and sanitary facilities have become a major issue, especially for people with special needs (Jayasiri et al., 2018b). Currently, the cooperation of local government and sub-national administrative officials in the country related to evacuation planning is not satisfactory (Perera et al., 2020). Lack of funding, lack of preparedness on evacuation plans, less information, and limited use of technology can be identified as major reasons behind these existing conditions (Malalgoda, 2014).

Moreover, public trust and awareness of disaster evacuation plans have decreased considerably in the country due to reasons such as conducting training drills without prior notices to the public (Pitigala Liyana Arachchi et al., 2021; Rathnayake et al., 2020). During the existing evacuation process, the needs of vulnerable groups such as older adults, differently-abled people, etc. have been neglected (Perera et al., 2020). Furthermore, irregularities due to gender and ethnic biases have caused several issues in the allocation of resources such as food and first aid for victims (Rathnayake et al., 2020). Currently, the use of schools as evacuation shelters has been promoted by authorities. However, it has become an issue since newly constructed schools and other public buildings in coastal areas are located in lowland areas that get inundated during a tsunami (Ministry of Education, 2008; Rathnayake et al., 2020). 
The impacts of pandemics on evacuation and shelter management cannot be neglected. Response mechanisms for concurrent hazards during COVID-19 have disrupted social distancing and containment measures and vice versa (Quigley et al., 2020; UNDRR and OCHA, 2020). Therefore, appropriate health guidelines and containment measures should be followed during evacuation and within shelter sites. In addition, failures can occur in logistic management in areas hit hard by multiple hazards amidst a pandemic (Abkowitz, 2020). These synergized impacts of multiple hazards during the pandemic have adversely affected people who are already vulnerable. The negligence of such groups from social protection measures taken by authorities creates severe issues (UNDRR and OCHA, 2020). In this regard, authorities in Sri Lanka have launched several initiatives such as establishing designated shelters in COVID-19 risk areas and the concept of 'Friends and Relatives' which directs victims to the residences of their friends and relatives (WFP, 2020). However, the occurrence of recent southwest monsoon showers has highlighted the dire need for emulating multi-sectoral approaches to address the impacts of multiple hazards during COVID-19 and other pandemics in the country.

\subsection{Response of community}

Even if EW and EP mechanisms are developed by authorities up to standards, the effectiveness can be affected by the response capability of the community. Lack of knowledge on disasters has made the coastal community more vulnerable to coastal disasters such as tsunamis. The businessoriented lifestyle has become a leading cause in this regard (Hippola et al., 2020). The majority of the coastal community is not aware of decision-makers, modes of EW dissemination, impacts of disasters, etc. Lack of awareness and knowledge of new communication platforms through which TEWs are disseminated can be recognized as another barrier to coastal disaster resilience (Jayasiri et al., 2018a). Sometimes the level of public trust in EW mechanisms has been drastically reduced 
due to situations such as false alarms, thus the response capacity of vulnerable communities for TEWs is reduced.

The reluctance of the public to evacuate leaving their personal properties is another key issue among coastal communities. In general, elderly people's likelihood of evacuation is considerably low (Smith et al., 2017). Fear of thievery, lack of trust in EW messages, and lack of facilities in shelters have become leading causes of public reluctance to evacuate. Furthermore, the inclusion of people with special needs in response mechanisms in the community level needs more focus. Information from the Department of Census and Statistics, Sri Lanka has revealed that more than $7 \%$ of the population in the coastal districts are differently-abled (Department of Census and Statistics (DoCS), 2012; Stough and Kang, 2015). Under existing conditions, local actors and volunteers at the community level act as the first responders in most disasters. But restrictions on mobility during the COVID-19 outbreak have hampered their capacities (UNDRR, 2020a). The significance of adhering to health guidelines on measures such as social distancing and use of masks [except stay home orders] during response mechanisms for hazards is greatly highlighted (Lux, 2020). Such issues call for the need for paying attention to modifications in the emergency response mechanisms at the community level taking into account the impacts of multiple risks especially during tsunamis due to their higher impacts.

\subsection{A summary of key areas addressed in past studies}

A summary of key areas addressed in past studies carried out by the research team can be identified as shown in Table 2.

Table 2: A summary of key areas addressed by past studies of the research team

\begin{tabular}{|l|l|}
\hline Key area & Reference \\
\hline Governing structures & (Rathnayake et al., 2020, Jayasiri et al., 2018) \\
\hline Evacuation planning & $\begin{array}{l}\text { (Hippola et al., 2020; Jayasiri et al., 2018a; Perera } \\
\text { et al., 2020) }\end{array}$ \\
\hline
\end{tabular}




\begin{tabular}{|l|l|}
\hline Community resilience & (Perera et al., 2020; Rathnayake et al., 2020) \\
\hline Response to EW messages & (Jayasiri et al., 2020; Perera et al., 2020) \\
\hline $\begin{array}{l}\text { Internal communication between technical } \\
\text { agencies }\end{array}$ & (Shehara et al., 2019b) \\
\hline Use of technological applications & (Shehara et al., 2019a) \\
\hline Use of social media for EW dissemination & Not addressed \\
\hline Impacts pandemics on response mechanisms & Not addressed \\
\hline
\end{tabular}

It is evident that the use of social media for EW dissemination and the impacts of pandemics on response mechanisms pertaining to tsunami and other coastal hazards have not been addressed adequately. Therefore, this paper has aimed at evaluating the use of social media for EW and EP dissemination in Sri Lanka focusing on the risk of tsunamis mainly. The authors have considered the findings and recommendations of Perera et al, (2020) as a base and aimed at further improving them with challenges and barriers in areas that have not been addressed previously. Furthermore, the authors have tried to identify shortcomings and relevant recommendations related to both vulnerable communities and relevant authorities and presented them separately in this paper.

\section{Methodology}

Primarily a detailed review was carried out on past studies conducted by the research team on coastal disaster resilience and impacts of pandemics in Sri Lanka and recently published reports. As described above in section 3, the scope of the study was identified based on the findings of this review. In the next phase, a comprehensive literature review was carried out to identify key parameters of using social media in disaster communication. Based on the findings of the literature review, a conceptual framework was developed for social media use during disasters in the Sri Lankan context. Consequently, an online questionnaire was developed based on the framework to identify the current status of use of social media in disaster communication in Sri Lanka. The online questionnaire was developed using the Survey Monkey platform. The developed questionnaire survey was circulated among the general public through social media platforms. The estimated average time to complete this survey was 15-20 mins. At the end of the data collection period, 408 responses were collected and only $352(86.27 \%)$ respondents had fully completed the questionnaire. Data obtained from the survey were analysed to identify the current status of social 
media use for disaster communication in Sri Lanka. Insights from the questionnaire were further used to recommend the use of social media to address existing gaps in EW and EP pertaining to tsunamis in Sri Lanka.

\section{Findings}

During past studies carried out by the research team in 2019, a survey was administered across 10 Grama Niladhari (GN) divisions in Sri Lanka to identify the feasibility of using mobile apps in disaster Early Warning mechanisms in the country. Results of the survey revealed that $68 \%$ of the respondents have never used any social media application, while $32 \%$ of respondents have frequently used somewhat of social media applications. Furthermore, the study has highlighted that most of the respondents in the age group: 40-50 years have never used Facebook and Twitter (Shehara et al., 2021, 2020). However, social media has been playing a vital role during the COVID-19 pandemic to disseminate risk information and updates on the pandemic to the general public. Many Facebook pages, Facebook groups, and WhatsApp groups have been created to disseminate COVID-19 related information by various stakeholders such as news media, community groups, etc. (Jayathilaka et al., 2021). 


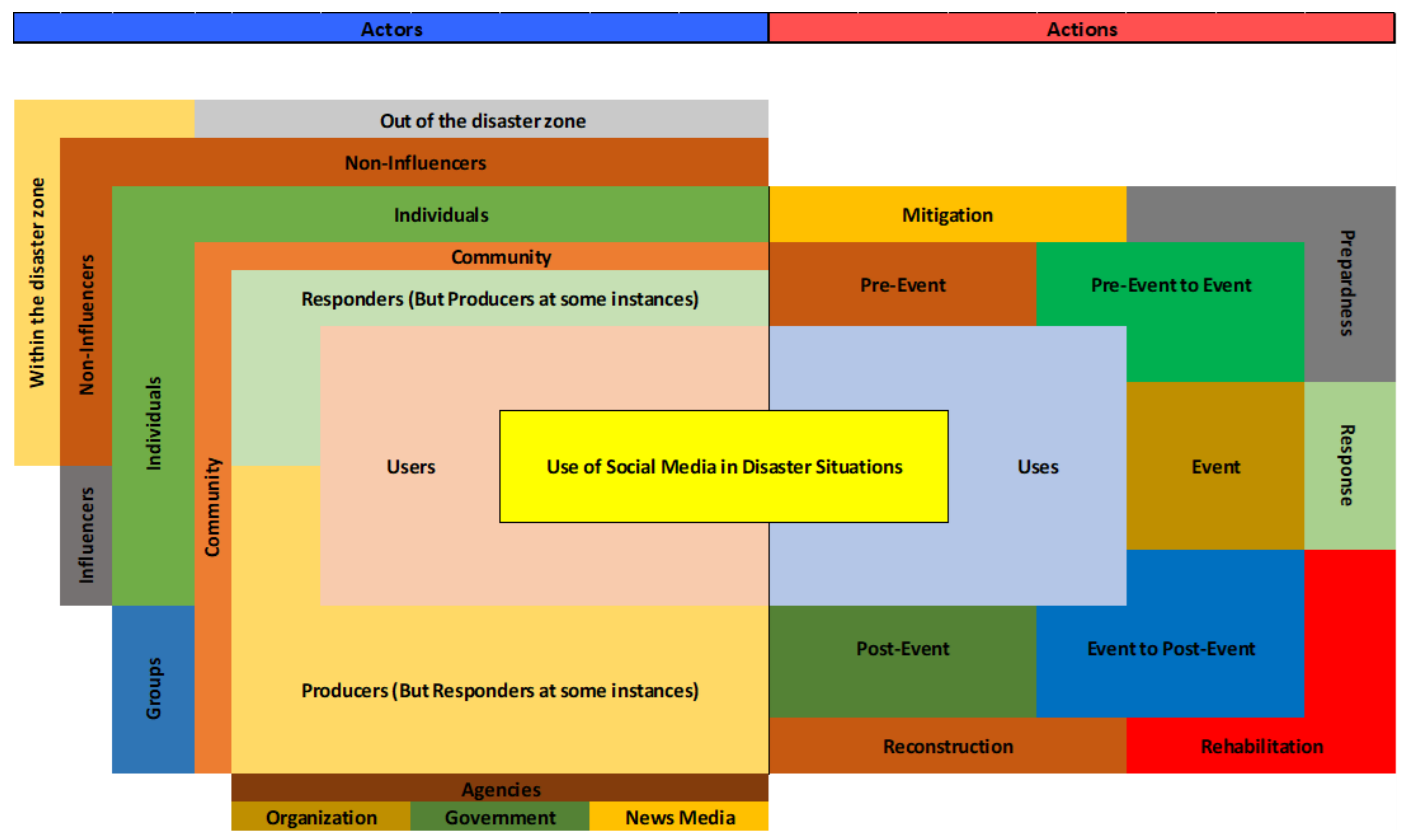

Figure 3: The proposed preliminary framework for use of Social Media in Disasters

In order to enhance the implementation of social media during disasters, a conceptual framework has been proposed through the study carried out by Jayathilaka et al., (2021). This framework has been developed mainly under two categories namely, 'Actions' and 'Actors'. Under the category of 'Actors', different users of social media during disasters have been illustrated and under the category of 'Actions', different uses of social media during disasters have been discussed. The proposed preliminary framework is presented in Figure 3.

The online questionnaire that was utilised in the present study was developed based on the above conceptual framework. Responses of the survey were analysed to investigate the relationship between the use of social media in disaster communication and the selected independent variables [Age, gender, and previous experience]. In this regard, the Binary logistic regression method was used to model the relationship between the selected variables. Results from a full model considering all predictor variables were included in Block 1. The contribution of each predictor (independent) variable to the model and its statistical significance has been evaluated in this Block. Table 3 details results after performing a series of statistical tests using SPSS v.26 software. 


\begin{tabular}{|c|c|c|c|c|c|}
\hline \multicolumn{6}{|c|}{ Variables in the equation } \\
\hline \multicolumn{2}{|c|}{ Variables } & \multirow[t]{2}{*}{$B$} & \multirow[t]{2}{*}{ S.E. } & \multirow{2}{*}{$\begin{array}{l}\text { Sig. } \\
.045\end{array}$} & \multirow[t]{2}{*}{$\operatorname{Exp}(B)$} \\
\hline Step $1^{\mathrm{a}}$ & Age & & & & \\
\hline & Age $(1)(<18)$ & 1.162 & .681 & .088 & 3.197 \\
\hline & $\begin{array}{l}\text { Age (2) (18- } \\
24)\end{array}$ & .718 & .649 & .269 & 2.051 \\
\hline & $\begin{array}{l}\text { Age (3) (25- } \\
34)\end{array}$ & -.005 & .724 & .994 & .995 \\
\hline & $\begin{array}{l}\text { Age (4) (35- } \\
44)\end{array}$ & -.214 & .740 & .772 & .807 \\
\hline & $\begin{array}{l}\text { Age (5) (45- } \\
54)\end{array}$ & .174 & .818 & .832 & 1.190 \\
\hline & $\begin{array}{l}\text { Age (6) (55- } \\
64)\end{array}$ & 1.063 & 1.248 & .394 & 2.894 \\
\hline & Gender (1) & -.042 & .262 & .873 & .959 \\
\hline & $\begin{array}{c}\text { Previous } \\
\text { Experience }\end{array}$ & .017 & .013 & .174 & 1.018 \\
\hline & Constant & .310 & .695 & .655 & 1.364 \\
\hline
\end{tabular}

A set of key insights were derived based on the results of the data analysis. It was revealed that gender is a non-significant predictor which means that there is no relationship between the use of social media and gender. Furthermore, previous experience of respondents on disasters has caused an increase in the use of social media during disasters in Sri Lanka. Considering the age group variables, it can be concluded that people who are within the age of 18-24 years are more likely to use social media during disasters relative to the other age groups. People between the ages of 2534 years also have used social media to a significant extent during disasters. By considering the value of the regression coefficient (B), it can be seen that the use of social media is low among respondents of age groups 25-34 and 35-44. However, a higher level of social media use for disaster communication was observed among respondents of 55-64 years and 65+ years.

According to a report published by the Department of Census and Statistics of Sri Lanka on Computer Literacy Statistics, people who are in the age group of 20-24 have the highest digital literacy in the country and it decreases with age. Furthermore, this report has illustrated that the Sri Lankans in the age group 20 - 24 indicate a higher internet and email usage compared to other 
age groups. Also, the use of digital devices such as Smartphones and Tablets which are connected to the internet is high in the same age group (DoCS, 2020). Moreover, the Asia Pacific Institute of Digital Marketing reveals that the Sri Lankan population in the age group 19-24 check their mobile phone at least 10 times per day. Further, they highlight that the number of times that people check their phones has reduced with the age. Elaborating on the use of disaster communication modes among older populations, past studies reveal that people who are in older age groups are more attracted to television programs such as news than digital platforms (Shehara et al., 2020). Therefore, it is evident that the penetration of the internet is comparatively low among older age groups in Sri Lanka. These aspects have resulted in low usage of social media among older age groups as depicted in the findings of the study. In this study, it has been identified that there is an increase in the usage of social media after the age of 55 years. In Sri Lanka, government and private sector employees are allowed to retire at the age of 55 years. Past studies reveal that older adults tend to use social media more after their retirement since social media provides a new platform to maintain their past connections with geographically disbursed colleagues (Meraz, 2009; Wang et al., 2011). This can be a possible reason for the increase in the use of social media after the age of 55 years.

Even though there is a slightly high usage of mobile apps among the community during disasters, this study has revealed that the consumption of social media during disasters by the Sri Lankan community is considerably low. Therefore, it is required to take immediate actions to adapt to technological advancements to effectively function during the disaster emergency response stage in the Sri Lankan context. However, the use of social media can cause negative impacts as well. Elaborating on this, false information can spread rapidly through social media causing severe consequences due to the lack of proper regulations. During the Indian Ocean-wide tsunami warning and response exercise (IOWave20) in Sri Lanka, a commotion occurred in the Beruwala area since a letter issued for testing purposes was misinterpreted as a genuine tsunami alert. This misinformation was circulated via social media leaving coastal communities in a state of panic (Daily Mirror, 2020).

Based on the results of the survey and the review of past studies conducted by the research team, gaps and recommendations in EW mechanisms and EP in coastal areas in Sri Lanka derived by Perera et al., (2020) can be further improved to present a holistic view of existing gaps and challenges pertaining to tsunamis and other coastal hazards [see Tables 4 and 5]. Table 4 presents 
identified gaps related to relevant authorities while identified gaps related to coastal communities are presented by Table 5 . 


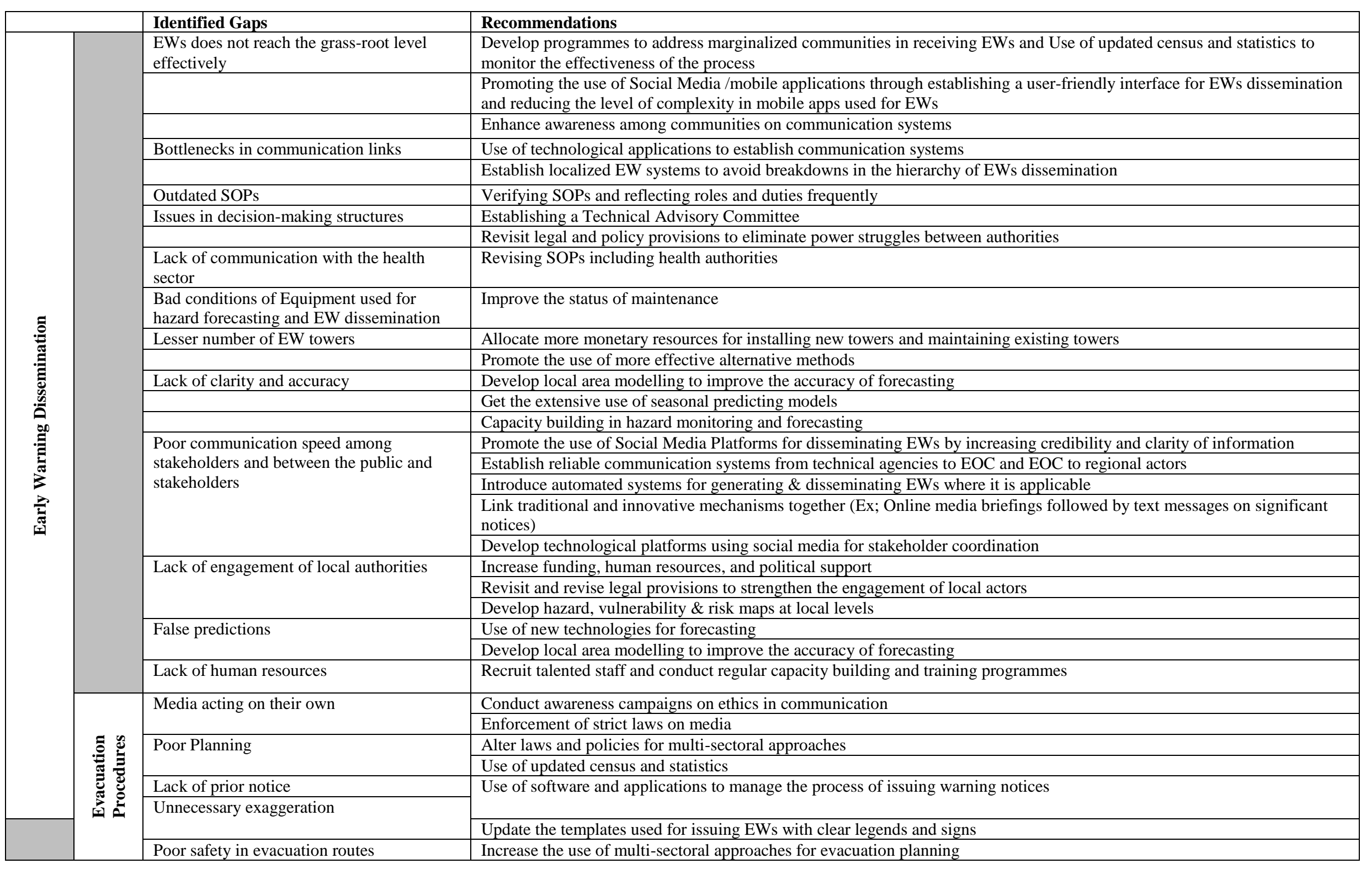




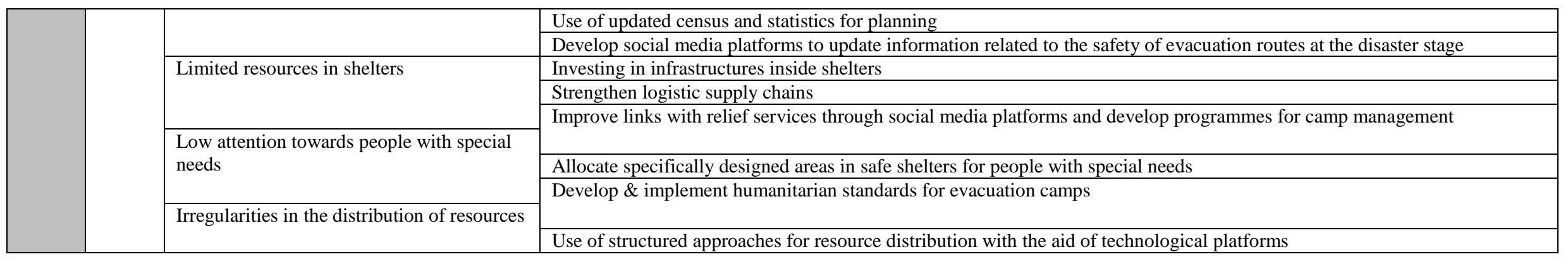

Table 5: Summary of identified gaps related to community and proposed recommendations

\begin{tabular}{|c|c|c|c|}
\hline & & Identified Gaps & Recommendations \\
\hline \multirow{16}{*}{\multicolumn{2}{|c|}{ 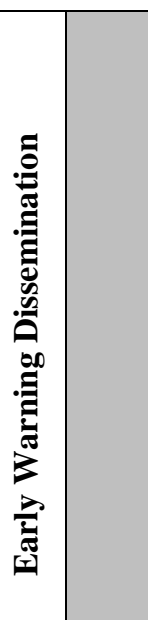 }} & \multirow[t]{3}{*}{ Mistrust on authorities } & Implement mechanisms to measure public trust and take actions accordingly \\
\hline & & & Introduction of rating systems for community trust on authorities \\
\hline & & & Implement rumour monitoring systems to eliminate false risk warnings \\
\hline & & \multirow[t]{3}{*}{ Overconfidence in their safety } & Persuade to evacuate by using strict notices and warnings \\
\hline & & & Build risk knowledge of community \\
\hline & & & Use of risk communication strategies to emphasize the danger of the hazard \\
\hline & & \multirow{2}{*}{$\begin{array}{l}\text { Lesser use of technological platforms for } \\
\text { information }\end{array}$} & Awareness campaigns for increasing electronic literacy \\
\hline & & & Dissemination of EWs through social media targeting specific age groups \\
\hline & & \multirow[t]{4}{*}{ Depends on slower modes of dissemination } & Communicate through tri forces \\
\hline & & & Increase the community awareness on speed communication systems \\
\hline & & & Establish communication systems from local actors to community \\
\hline & & & Updating school curriculum on risk communication systems \\
\hline & & \multirow[t]{4}{*}{ Lack of awareness \& not following health guidelines } & \\
\hline & & & Establishing clear signboards to disseminate proper information \\
\hline & & & Using informal tools of education \\
\hline & & & Community-based awareness programs \\
\hline & \multirow{11}{*}{ 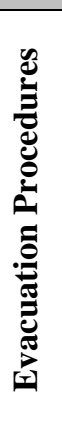 } & \multirow[t]{2}{*}{ Reluctance to respond } & Use clear signs in communicating the risk \\
\hline & & & Awareness building programmes to increase the level of risk knowledge on impacts of disasters \\
\hline & & \multirow[t]{4}{*}{ Inexperience in evacuation drills } & Emulate a multi-sectoral approach when designing and conducting evacuation drills \\
\hline & & & Scenario-based drills and training \\
\hline & & & Conduct an adequate number of drills at the community level \\
\hline & & & Promote benefits of pre-evacuation drills to increase participation in drills \\
\hline & & \multirow[t]{2}{*}{ Too attached to personal belongings } & Promote the concept of evacuation backpack \\
\hline & & & Educate on inhouse protection strategies for personal belongings Ex; Increase elevation to protect goods from floods \\
\hline & & \multirow[t]{3}{*}{ Poor cooperation with local government units } & Creating a personal care network \\
\hline & & & Include local authorities and community during evacuation planning \\
\hline & & & Establish platforms strengthen collaboration between LAs and communities \\
\hline
\end{tabular}




\section{Conclusion}

The findings of the study led to the identification of several gaps in TEWs and Evacuation Planning in Sri Lanka followed by recommendations as summarized in Tables 4 and 5. Taking into consideration the impacts of tsunamis and coastal hazards during the COVID-19 pandemic and its cascading impacts, these recommendations can be presented under key themes named, 1) Governance; 2) Institutional coordination; 3) Hazard forecasting and dissemination, and 4) Response at local and community level. Elaborating on proposed changes in governance, decisionmaking structures in the national early warning system should be further strengthened with the appointment of advisory committees and redesigned policies. As highlighted during past studies, power struggles between government authorities should be solved through the policy redesigning process. Furthermore, there should be a strong legal and policy basis to implement responses to concurrent hazards that can affect multiple sectors and levels of authority. Since response mechanisms to simultaneous hazards aggravate impacts of the pandemic, emergency preparedness and response mechanisms and contingency plans should be modified considering containment measures taken to curtail the pandemic. In modifying those plans, it is recommended to promote the use of technological platforms such as social media and mobile applications for risk communication and awareness-raising since it reduces human contacts and delays in information sharing. Furthermore, the complexity of these procedures should be reduced.

A strong level of coordination between relevant stakeholders of a Multi-Hazard Early Warning system is paramount in addressing synergized impacts of multiple disasters. As per identified gaps, the disaster management authorities in the country should align with public health authorities to effectively respond to possible tsunami and other hazards amidst COVID-19. Apart from the changes at the policy level, this collaboration can be further enhanced through creating technological platforms such as social media groups, virtual meeting groups, mobile applications, etc. during preparedness and response planning. Currently, the effectiveness of hazard forecasting and EW dissemination is a major concern for authorities. The use of local area modelling and extensive use of seasonal prediction models can be incorporated in increasing the level of accuracy in hazard prediction. Furthermore, the use of pandemic and tsunami and other hazards hybrid models enables to foresee compound effects of multiple disasters. Though local level actors have a high potential to reach the community level and carry out preparedness and response activities, 
this link has become weak under existing conditions. Increasing human resources, political support, funding, technical capacities, etc. can be identified as possible strategies for enhancing the capacity of local actors. Through strengthening local actors, several issues related to evacuation planning such as lack of pre-evacuation drills, emergency signs, poor dissemination of evacuation plans, poor facilities at safety centres, and commotions in resource distribution can be addressed effectively.

Poor last-mile dissemination, lack of public trust in authorities, lack of awareness, dependency on slower communication modes are a few of the leading issues identified at the community level pertaining to early warning systems for tsunamis and other hazards. Elaborating on possible reasons behind those issues, the overall adaptation to the newest technology for communication in an event of a disaster is comparatively low in the Sri Lankan community. As per the findings, there is low usage of social media for communicating disaster-related information and it does not depend on the gender of users but the age group. There should be a mechanism to increase the use of social media platforms for disaster communication among the middle age groups (35-54 years). In this regard, strategies should be implemented to increase digital literacy and access to the internet among older adults. Though older adults do not use social media much they can be highly motivated when they identify how it can be useful to their lives. Furthermore, authorities have the responsibility of getting the maximum use of the population (18-34 years and 55+ years who use social media and technological platforms for disaster communication. Creating internet platforms with easy access for disaster communication, user-friendly and informative interfaces in mobile applications, and less complexity in messages disseminated through social media can be identified as some of the possible actions to be taken to increase the use of social media for EW dissemination. At the same time, necessary actions should be taken to eliminate false information shared through those platforms. Having dedicated staff to quell rumours and misinformation, strict law enforcement, and use of ethics in communications can be recommended in this regard. If relevant authorities can create an environment where EWs and EP are disseminated effectively through social media platforms, issues such as lack of public trust, repetitive notices, lack of prior notices on safety drills, and poor public awareness can be addressed through such platforms. As a way forward this research can be extended to identify how impacts of infectious disease outbreaks such as COVID-19 can affect the use of social media to receive and share information related to EW and EP during a multi-hazard scenario, especially during a tsunami-pandemic hybrid event. 


\section{Acknowledgment}

The authors here gratefully acknowledge Erasmus+ Capacity Building for Higher Education Grant, Capacity Building in Asia for Resilience EducaTion (CABARET) for providing funds and expertise in carrying out this research study. The authors would also like to acknowledge the members of the research team who contributed to collect the data. 


\section{References}

Abkowitz, M., 2020. Can your community handle a disaster and coronavirus at the same time? | PreventionWeb.net. Conversat. Media Gr. .

Acar, A., Muraki, Y., 2011. Twitter for crisis communication: Lessons learned from Japan's tsunami disaster. Int. J. Web Based Communities 7, 392-402. https://doi.org/10.1504/IJWBC.2011.041206

Amaratunga, D., Haigh, R., Fernando, N., Jayasinghe, N., Siriwardana, C., Jayasekara, R., Jayaweera, S., 2020a. Position paper on the integration of epidemic and pandemic preparedness in disaster risk reduction planning in Sri Lanka.

Amaratunga, D., Haigh, R., Premalal, S., Siriwardana, C., Liyanaarachchige, C., 2020b. Report on Exercise Indian Ocean Wave 2020: An Indian Ocean-wide Tsunami Warning and Communications Exercise.

Bernard, E., Titov, V., 2015. Evolution of tsunami warning systems and products. Philos. Trans. R. Soc. A Math. Phys. Eng. Sci. 373, 20140371. https://doi.org/10.1098/rsta.2014.0371

Birkmann, J., Buckle, P., Jaeger, J., Pelling, M., Setiadi, N., Garschagen, M., Fernando, N., Kropp, J., 2010. Extreme events and disasters: A window of opportunity for change? Analysis of organizational, institutional and political changes, formal and informal responses after mega-disasters. Nat. Hazards 55, 637-655. https://doi.org/10.1007/s11069008-9319-2

Cecioni, C., Bellotti, G., Romano, A., Abdolali, A., Sammarco, P., Franco, L., 2014. Tsunami early warning system based on real-time measurements of hydro-acoustic waves, in: Procedia Engineering. Elsevier Ltd, pp. 311-320. https://doi.org/10.1016/j.proeng.2014.02.035

Department of Census and Statistics (DoCS), 2012. Information on Disabled Persons.

Disaster Management Centre, 2020a. Early Warning Systems [WWW Document]. URL http://www.dmc.gov.lk/index.php?option=com_content $\&$ view=article\&id=60\&Itemid=225 \&lang=en (accessed 10.30.20).

Disaster Management Centre, 2020b. Standard Operating Procedures for Sri Lanka's Tsunami Early Warning System.

Disaster Management Centre, 2015. National Emergency Operation Plan Volume 1 (NEOP) [WWW Document]. URL https://www.unlocked.lk/wp-content/uploads/2019/06/NEOPVolume-1.pdf

Disaster Management Centre, 2014. Sri Lanka National Disaster Management Plan 2013-2017.

DoCS, 2020. Computer Literacy Statistics - 2020 (First six months). Department of Census and Statistics.

Eckstein, D., Marie-Lena, H., Maik, W., 2019. Global Climate Risk Index 2019.

Feldman, D., Contreras, S., Karlin, B., Basolo, V., Matthew, R., Sanders, B., Houston, D., Cheung, W., Goodrich, K., Reyes, A., Serrano, K., Schubert, J., Luke, A., 2016. Communicating flood risk: Looking back and forward at traditional and social media outlets. Int. J. Disaster Risk Reduct. 15, 43-51. https://doi.org/10.1016/j.ijdrr.2015.12.004

Fernando, R.L.S., 2020. Artificial Intelligence and Disaster Management in Sri Lanka: Problems and Prospects. Palgrave Macmillan, Singapore, pp. 149-166. https://doi.org/10.1007/978981-15-4291-6 11

Finau, G., Cox, J., Tarai, J., Kant, R., Varea, R., Titifanue, J., 2018. Social Media and Disaster Communication: A Case Study of Cyclone Winston. Pacific Journal. Rev. 24, 123-137. 
https://doi.org/https://doi.org/10.24135/pjr.v24i1.400

Haigh, R., Amaratunga, D., Hemachandra, K., 2018. A capacity analysis framework for multihazard early warning in coastal communities, in: Procedia Engineering. Elsevier Ltd, pp. 1139-1146. https://doi.org/10.1016/j.proeng.2018.01.147

Haigh, R., Sakalasuriya, M., Amaratunga, D., Basnayake, S., Hettige, S., Premalal, S., Jayasinghe Arachchi, A., 2020. The upstream-downstream interface of Sri Lanka's tsunami early warning system. Int. J. Disaster Resil. Built Environ. 11, 219-240. https://doi.org/10.1108/IJDRBE-07-2019-0051

Hazarika, B., Rea, A., Mousavi, R., Chen, K., 2020. The impact of social media on disaster relief effort - recovery coordination for Hurricane Harvey. Glob. Knowledge, Mem. Commun. https://doi.org/10.1108/GKMC-05-2020-0062

Hettiarachchi, S.S.L., Weerasinghe, S., 2014. Achieving Disaster Resilience through the Sri Lankan Early Warning System: Good Practices of Disaster Risk Reduction and Management. Procedia Econ. Financ. 18, 789-794. https://doi.org/10.1016/s22125671(14)01003-X

Hippola, H.M.S.S., Jayasooriya, E.M.S.D., Jayasiri, G.P., Randil, C., Perera, C., Sylva, K.K.K., Kulathunga, A.K., Bandara, C.S., Siriwardena, C.S.A., Dissanayake, P.B.R., 2020. Gap Assessment of Warning and Dissemination Process of Early Warning System in Coastal Areas of Sri Lanka, in: Lecture Notes in Civil Engineering. Springer, pp. 36-44. https://doi.org/10.1007/978-981-13-9749-3_4

International Tsunami Information Center, 2021. Global System - [WWW Document]. URL http://itic.iocunesco.org/index.php?option=com_content $\&$ view=category\&layout=blog $\&$ id=2005\&Itemi $\mathrm{d}=2005$. (accessed 1.30.21).

IOC/UNESCO, 2015. Tsunami risk assessment and mitigation for the Indian Ocean; knowing your risk and what to do about it [WWW Document]. URL http://ioc/UNESCO (accessed 1.27.21).

Jayasekara, P.K., 2019. Role of Facebook as a disaster communication media. Int. J. Emerg. Serv. 8, 191-204. https://doi.org/10.1108/IJES-04-2018-0024

Jayasekara, R., Siriwardana, C., Amaratunga, D., Haigh, R., 2021. Analysing the effectiveness of varied stakeholder segments in preparedness planning for epidemics and pandemics in Sri Lanka: Application of Social Network Analysis (SNA), in: COVID 19: Impact, Mitigation, Opportunities and Building Resilience From Adversity to Serendipity. National Science Foundation, Sri Lanka, pp. 540-553.

Jayasiri, G.P., Randil, O.P.C., Perera, G.M.C.A., Siriwardana, C.S.A., Dissanayake, P.B.R., Bandara, C.S., 2020. Important Aspects of Evacuation Planning for the Coastal Communities in Sri Lanka, in: Lecture Notes in Civil Engineering. Springer, pp. 3-10. https://doi.org/10.1007/978-981-13-9749-3_1

Jayasiri, G.P., Randil, O.P.C.A., Perera, G.M., Siriwardana, C.S.A., Dissanayake, P.B.R., Bandara, C.S., 2018a. Important Aspects of Evacuation Planning for the Coastal Communities in Sri Lanka, in: International Conference in Sustainable Built Environment ICSBE 2018. Kandy, Sri Lanka.

Jayasiri, G.P., Siriwardena, C.S.A., Hettiarachchi, S.S.L., Dissanayake, P.B.R., Bandara, C.S., 2018b. Evaluation of community resilience aspects of Sri Lankan Coastal Districts. Int. J. Adv. Sci. Eng. Inf. Technol. 8, 2161-2167. https://doi.org/10.18517/ijaseit.8.5.7095

Jayasuriya, S., Steele, P., Weerakoon, D., 2006. Post-Tsunami Recovery: Issues and Challenges 
in Sri Lanka. Asian Development Bank Institute and IPS.

Jayathilaka, H.., Siriwardana, C.S.A., Amaratunga, D., Haigh, R., Dias, N., 2021. Conceptual Framework for Social Media Use During Disasters, in: Amaratunga, D., Haigh, R., Dias, N. (Eds.), Multi-Hazard Early Warning and Disaster Risks. Springer International Publishing, London, UK.

JICA, 2017. Data collection survey on disaster risk reduction sector in Sri Lanka.

Johnson, K., 2015. Mobile Phones: News Consumption, News Creation, and News Organization Accommodations, in: Encyclopedia of Mobile Phone Behavior. IGI Global, pp. 280-286. https://doi.org/10.4018/978-1-4666-8239-9.ch024

Keim, M.E., Noji, E., 2011. Emergent use of social media: a new age of opportunity for disaster resilience. Am. J. Disaster Med. 6, 47-54.

Komoriya, C., 2018. Dealing with disaster in Japan. The Japan Times .

Lancaster, G., 2020. These 5 countries have advanced Tsunami warning systems [WWW Document]. UNITED NATIONS Off. DISASTER RISK Reduct. URL https://www.preventionweb.net/news/view/71115 (accessed 1.30.21).

Leon, J.C.. de., Borgardi, J., Dannenmann, S., Basher, R., 2006. Early Warning Systems in the context of disaster risk management. Entwicklung and LandlicherRum 40, 23-25.

Lux, S., 2020. Acting early in times of a pandemic: The challenge of staying ready for extremeweather events during COVID-19 - Forecast-based Financing [WWW Document]. Ger. Red Cross Soc. URL https://www.forecast-based-financing.org/2020/06/11/acting-early-intimes-of-pandemic/ (accessed 5.22.21).

Malalgoda, C.I., 2014. Empowering Local Governments in Making Cities Resilient to Disasters. University Salford, United Kingdom.

Meraz, S., 2009. Is there an elite hold? traditional media to social media agenda setting influence in blog networks. J. Comput. Commun. 14, 682-707. https://doi.org/10.1111/j.10836101.2009.01458.x

Ministry of Education, 2008. Towards a Disaster Safe School: National Guidelines for School Disaster Safety.

Mulligan, M., Nadarajah, Y., 2012. Rebuilding community in the wake of disaster: lessons from the recovery from the 2004 tsunami in Sri Lanka and India. Community Dev. J. 47, 353368. https://doi.org/10.1093/cdj/bsr025

Okura, Y., Nerupane, S., Bikrama, R., 2020. Avoiding a perfect storm; COVID-19 and floods in Nepal. Zurich Flood Resilience Alliance.

Pattiaratchi, C., 2005. Tsunami impacts on Sri Lanka-lessons for disaster reduction on coasts, in: International Symposium on Disaster Reduction on Coasts. Melbourne .

Peary, B.D.M., Shaw, R., Takeuchi, Y., 2012. Utilization of Social Media in the East Japan Earthquake and Tsunami and its Effectiveness. J. Nat. Disaster Sci. 34, 3-18. https://doi.org/10.2328/jnds.34.3

Perera, C., Jayasooriya, D., Jayasiri, G., Randil, C., Bandara, C., Siriwardana, C., Dissanayake, R., Hippola, S., Sylva, K., Kamalrathne, T., Kulatunga, A., 2020. Evaluation of gaps in early warning mechanisms and evacuation procedures for coastal communities in Sri Lanka. Int. J. Disaster Resil. Built Environ. 11, 415-433. https://doi.org/10.1108/IJDRBE-07-20190048

Pitigala Liyana Arachchi, I.S., Siriwardana, C., Amaratunga, D., Haigh, R., 2021. Evaluation of societal trust on multi-hazard early warning (MHEW) mechanism: Sri Lankan context. Int. J. Disaster Resil. Built Environ. ahead-of-print. https://doi.org/10.1108/IJDRBE-01-2021- 
0010

Quigley, M.C., Attanayake, J., King, A., Prideaux, F., 2020. A multi-hazards earth science perspective on the COVID-19 pandemic: the potential for concurrent and cascading crises. Environ. Syst. Decis. 40, 199-215. https://doi.org/10.1007/s10669-020-09772-1

Rasquinho, O., Leong, D., Liu, J., 2012. Brief Introduction to Synergized Standard Operating Procedures for Coastal Multi-Hazards Early Warning System. Trop. Cyclone Res. Rev. 1, 489-494. https://doi.org/10.6057/2012TCRR04.07

Rathnayake, D.K., Kularatne, D., Abeysinghe, S., Shehara, I., Fonseka, T., Edirisinghe Mudiyanselage, S.D.J., Kamalrathne, W.G.C.T., Siriwardana, C., Alagiyawanna Mohotti Appuhamilage, C.S.B., Dissanayake, R., 2020. Barriers and enablers of coastal disaster resilience - lessons learned from tsunami in Sri Lanka. Int. J. Disaster Resil. Built Environ. 11, 275-288. https://doi.org/10.1108/IJDRBE-07-2019-0050

Sakamoto, M., Kuri, M., Iguchi, M., Maki, N., Ichiko, T., Sekiya, N., Kobayashi, H., 2016. Disaster Governance in Disaster Management Planning -Analysis of the Evacuation Planning Process for Kuchinoerabujima Volcano Eruption-. J. Nat. Disaster Sci. 37, 105117. https://doi.org/10.2328/jnds.37.105

Shehara, I., Siriwardana, C., Amaratunga, D., Haigh, R., Bandara, C., Dissanayake, R., 2019a. An Overview of Existing Digital Platforms in Disaster Emergency Response Stage, in: SBE19 Malta International Conference| Sustainability and Resilience. Malta.

Shehara, I., Siriwardana, C.S.A., Amaratunga, D., Haigh, R., 2019b. Application of Social Network Analysis (SNA) to Identify Communication Network Associated with MultiHazard Early Warning (MHEW) in Sri Lanka, in: MERCon 2019 - Proceedings, 5th International Multidisciplinary Moratuwa Engineering Research Conference. Institute of Electrical and Electronics Engineers Inc., pp. 141-146. https://doi.org/10.1109/MERCon.2019.8818902

Shehara, P.L.A.I., Siriwardana, C.S.A., Amaratunga, D., Haigh, R., 2020. Examining the Community Perception towards Communication Modes of Issuing Multi-Hazard Early Warning (MHEW) in Sri Lanka, in: MERCon 2020 - 6th International Multidisciplinary Moratuwa Engineering Research Conference, Proceedings. Institute of Electrical and Electronics Engineers Inc., pp. 60-65.

https://doi.org/10.1109/MERCon50084.2020.9185325

Shehara, P.L.A.I., Siriwardana, C.S.A., Amaratunga, D., Haigh, R., Fonseka, T., 2021. Feasibility of Using Mobile Apps in Communication and Dissemination Process of Multihazard Early Warning (MHEW) Mechanism in Sri Lankan Context, in: Lecture Notes in Civil Engineering. Springer Science and Business Media Deutschland GmbH, pp. 177-189. https://doi.org/10.1007/978-981-15-7222-7_16

Shneiderman, B., Preece, J., 2007. 911.gov. Science (80-. ). https://doi.org/10.1126/science.1139088

Smith, P.J., Brown, S., Dugar, S., 2017. Community-based early warning systems for flood risk mitigation in Nepal. Nat. Hazards Earth Syst. Sci. 17, 423-437. https://doi.org/10.5194/nhess-17-423-2017

Stough, L.M., Kang, D., 2015. The Sendai Framework for Disaster Risk Reduction and Persons with Disabilities. Int. J. Disaster Risk Sci. 6, 140-149. https://doi.org/10.1007/s13753-0150051-8

Tomita, T., Imamura, F., Arikawa, T., Yasuda, T., Kawata, Y., 2006. Damage caused by the 2004 Indian Ocean Tsunami on the Southwestern coast of Sri Lanka. Coast. Eng. J. 48, 99- 
116. https://doi.org/10.1142/S0578563406001362

UNDRR, 2020a. Multiple-hazards and systemic risk: Addressing climate-related disasters in times of COVID-19 | PreventionWeb.net [WWW Document]. PreventionWeb. URL https://www.preventionweb.net/events/view/71946?id=71946. (accessed 1.12.21).

UNDRR, 2020b. COVID-19 Engagement Strategy Interim Report. Geneva, Switzerland.

UNDRR, OCHA, 2020. Combatting the dual challenge of COVID-19 and climate related disasters.

UNESCO, 2019. Indian Ocean Tsunami Warning and Mitigation System Functioning Autonomously [WWW Document]. URL https://en.unesco.org/news/indian-ocean-tsunamiwarning-and-mitigation-system-functioning-autonomously-0 (accessed 1.31.21).

UNISDR, 2016. Bangkok Principles for the implementation of the health aspects of the Sendai Framework for Disaster Risk Reduction 2015-2030. Bangkok, Thailand.

Wang, M., Henkens, K., van Solinge, H., 2011. A Review of Theoretical and Empirical Advancements. Am. Psychol. 66, 204-213. https://doi.org/10.1037/a0022414

WFP, 2020. Weather and Climate Outlook of Pre South-West Monsoon (May 2020) Sri Lanka. Wijetunge, J.J., 2012. Nearshore tsunami amplitudes off Sri Lanka due to probable worst-case seismic scenarios in the Indian Ocean. Coast. Eng. 64, 47-56.

https://doi.org/10.1016/j.coastaleng.2012.02.005

WMO, 2018. Multi-hazard Early Warning Systems: A Checklist. Geneva, Switzerland.

Yunarto, Y., Sari, A.M., 2018. Analysis of community tsunami evacuation time: An overview, in: IOP Conference Series: Earth and Environmental Science. Institute of Physics Publishing, p. 12033. https://doi.org/10.1088/1755-1315/118/1/012033 